\title{
COMPACT OPERATORS BETWEEN REAL INTERPOLATION SPACES
}

\section{LUZ M. FERNÁNDEZ-CABRERA}

Abstract. We show necessary and sufficient conditions for compactness of operators acting between real interpolation spaces.

Mathematics subject classification (2000): 46B70.

Key words and phrases: Real interpolation, compact operators, compacness of interpolated operators.

\section{REFERENCES}

[1] C. BenNETT AND R. Sharpley, Interpolation of operators, Academic Press, New York, 1988.

[2] J. BERGH AND J. LÖFSTRÖM, Interpolation spaces. An introduction, Springer, Berlin, 1976.

[3] Y. BRUdNYI AND N. KRUGLJAK, Interpolation functors and interpolation spaces, Vol. 1, North-Holland, Amsterdam, 1991.

[4] F. Cobos, M. CWIKel And P. Matos, Best possible compactness results of Lions-Peetre type, Proc. Edinb. Math. Soc. 44 (2001) 153-172.

[5] F. Cobos, L. M. Fernández-Cabrera, A. Martínez And E. PustylniK, Some interpolation results that are exclusive property of compact operators, Proc. Royal Soc. Edinburgh 132A (2002) (to appear).

[6] F. CoBOs, T. KÜHN AND T. SCHONBEK, One-sided compactness results for Aronszajn-Gagliardo functors, J. Funct. Analysis 106 (1992) 274-313.

[7] F. CoBos AND J. PEETRE, Interpolation of compactness using Aronszajn-Gagliardo functors, Israel J. Math. 68 (1989) 220-240.

[8] F. COBOS, L.-E. PERSSON, Real interpolation of compact operators between quasi-Banach spaces, Math. Scand. 82 (1998) 138-160.

[9] M. CWIKEL, Real and complex interpolation and extrapolation of compact operators, Duke Math. J. 65 (1992) 333-343.

[10] J. L. LiOns And J. PeEtre, Sur une classe d'espaces d'interpolation, Inst. Hautes Etudes Sci. Publ. Math. 19 (1964) 5-68.

[11] J. PEETRE, A theory of interpolation of normed spaces, Lecture notes, Brasilia 1963 [Notas Mat. 39 (1968) 1-86].

[12] A. PERSSOn, Compact linear mappings between interpolation spaces, Ark. Mat. 5 (1964) 215-219.

[13] T. SCHONBEK, Interpolation of compact operators by the complex method and equicontinuity, Indiana U. Math. J. 49 (2000) 1229-1245.

[14] H. TRIEBEL, Interpolation theory, function spaces, differential operators, North-Holland, Amsterdam, 1978. 